\title{
Burden of Hepatitis B, Hepatitis C and HIV Infections Among Adult Citizens in Kandahar City, Afghanistan
}

\author{
Khwaja Mir Islam Saeed (MD, MSc) ${ }^{1}$ \\ ${ }^{1}$ Head of Grant and Service Contract Management Unit (GCMU), Ministry of Public Health, Kabul- \\ Afghanistan, Tel: 0093700290955
}

\begin{abstract}
Background:Blood borne diseases including viral hepatitis are important public health challenges worldwide. There is a notable dearth of data about Hepatitis B Virus (HBV), Hepatitis C Virus (HCV) and HIV prevalence in Afghanistan. The objective of this study was to estimate the seroprevalence of HBV, HCV, HIV infections among adult populations in Kandahar city, Afghanistan.

Methods and Materials:A total of 1165 adult citizens in Kandahar city were included in the study using a cross-sectional design in October-November 2015. Data on demographic, socioeconomic and lifestyle factors were collected using WHO STEP wise approach. Rapid tests were conducted to identify the prevalence of HBV, HCV, and HIV infections. Statistical analysis performed Using SPSS v.20.

Results: Of total records, females constituted almost half 597 (51.2\%) with overall mean age of $38.3 \pm 11.2$ years. The prevalence of HBV was $2 \%$ (22 out of 1153) for HBsAg on rapid test and 12 subject (1\%) were seropositive for anti-HCV on rapid tests. None of subjects had co-infections. None of specimen were positive for HIV infection showed zero prevalence. Proportion of married groups was $79.3 \%$, illiteracy rate was $73.2 \%$ and $88.5 \%$ of women were at home doing housework (housewives). About one tenth $(9.7 \%)$ were smokers and $16.3 \%$ were snuffers. There was no statistical association of studied factors with HBV and HCV.

Conclusion: The study found low prevalence of HBV and HCV in adult citizens in Kandahar city. Public awareness and health education regarding risk factors for viral hepatitis and encouragement for vaccination is recommended. More focus is needed to be given to high risk groups due their vulnerability to diseases.
\end{abstract}

Keywords: Hepatitis, HBV, HCV, HIV infection, risk factors, Afghanistan

\section{INTRODUCTION}

The Hepatitis B virus (HBV) is blood born virus and a serious public health problem worldwide. It has a major cause of morbidity and mortality, touching almost every class of person and age group with vertical transmission, the commonest route of transmission in many endemic areas [1]. World Health Organization (WHO) estimates that more than 2 billion people have been infected with HBV and 350 million people across the world continue to carry chronic infection, of which almost 1 million die annually from HBV related liver disease [2]. The prevalence of $\mathrm{HBV}$ is ranging from below $2 \%$ in low endemic countries to greater than $8 \%$ in high endemic countries [3]. HBV infection is transmitted by parenteral route, by percutaneous or per-mucosal exposure to blood or other body fluids. In low endemic regions, most cases of hepatitis B are related to sexual exposure, while in high endemic areas perinatal or early childhood transmission is the most common form [4]. During the last two decades, serological, virological, biochemical, and histological diagnostic tools are used frequently to monitor and characterize the clinical state of HBV infection. One of the first serologic markers appearing after $\mathrm{HBV}$ infection is Hepatitis B surface antigen (HBsAg). Its persistence for more than 6 months reveals chronic HBV infection [5]. Europe, Asia, Africa, the Middle East, and the Pacific basin population are places where HBV is the leading cause of cirrhosis and hepatocellular carcinoma (HCC) [6-7]. The prevalence of HBV and its modes of transmission vary geographically, and it can be classified into three endemic patterns [8-10]. Around $45 \%$ of the world's population live in regions of high endemicity, defined as areas where $8 \%$ or more of the population are positive for HBsAg such as Southeast Asia and Sub-Saharan Africa. The moderately endemic areas, such as in Mediterranean countries and Japan, are defined as those areas where $2-7 \%$ of the population are HBsAg positive, and around $43 \%$ of the world's population live in regions of moderate endemicity. Western Europe and North America are considered as areas with low endemicity $(<2 \%$ of the population is HBsAg positive) and it constitutes $12 \%$ of the world's population [8, 11].Certain types of behaviors increase the risk for contracting $\mathrm{HBV}$ such as: use of contaminated needle during acupuncture, intravenous drug abuse, ear piercing and tattooing, sexually active heterosexuals or homosexuals, infants/children in highly endemic areas, infants born to infected mothers, health care workers, hemodialysis patients, blood receivers prior (blood transfusion), hemophiliacs, prisoners with long term sentences as well as visitors to highly endemic regions [11]. Furthermore, having concurrent infections including HBV, HCV and HIV infections make the situation worse and requires complex management. 
Hepatitis C Virus (HCV) infection is being recognized as a global health problem. Around 170 million people are chronically infected and 3-4 million are newly affected every year [12]. Most of the patients are asymptomatic till the disease is at its terminal stage posing a great danger to spread this infection silently [13]. There is currently no vaccine available for HCV infection prevention due to the high degree of strain variation [14]. Of the five hepatitis viruses (A, B, C, D and E), chronic hepatitis B virus (HBV) infection and hepatitis C virus $(\mathrm{HCV})$ infection have the greatest impact on morbidity and mortality and together resulted in an estimated 1.4 million deaths in 2010 [15-16]. In Pakistan a weighted average of hepatitis B antigen prevalence in pediatric populations was $2.4 \%$ and for hepatitis $\mathrm{C}$ antibody was $2.1 \%$. A weighted average of hepatitis $\mathrm{B}$ antigen prevalence among healthy adults was $2.4 \%$ (range $1.4-11.0 \%$ ) and for hepatitis $\mathrm{C}$ antibody was $3.0 \%$ [17]. In the Middle East region, the prevalence of HBV carriers among adults varies from less than 2\%, as in Bahrain, to more than $15 \%$, as in the Republic of Yemen [18]. In a study which was conducted in Lahore Pakistan among tested samples $4.9 \%$ of the subjects were confirmed to harbor active HCV infections in adult population without gender difference [19]. In a hospital based study in Pakistan it was reported that hepatitis B and C was present in $5.15 \%$ of which $3.12 \%$ were suffering from hepatitis $\mathrm{C}$ and $2.02 \%$ were suffering from hepatitis B while coinfection was present in $0.12 \%$ patients [20].

The burden of Hepatitis and HIV infection is poorly available in Afghanistan due to few surveys conducted, however the country lies in intermediate level of prevalence for HBV and high risk for HIV infection.UNAIDS data indicate that the epidemic of HIV infection is presently remains under $<0.1 \%$ among the general population in Afghanistan, yet has the potential to grow quickly from a small base of injecting drug users to their sexual partners and thus to heterosexual men and women unless effective, vigorous, and sustained action is taken early [21]. A prevalence study in Jalalabad city among adult population reported that $3.8 \%$ were seropositive for HBsAg on rapid test and 3.4\% were confirmed positive after ELIZA. Totally $0.9 \%$ were seropositive for anti-HCV on rapid tests. Independent predictors for HBsAg infection were being male (p-value $<0.01$ ) traditional practice of tattooing ( $\mathrm{p}$-value $<0.05$ ) and history of jaundice (p value <0.001) [22]. The overall prevalence of HBV and HCV among injecting drug users were 6.5\% and 36.6\% respectively in 2005-2006 [23]. In 2005 it is estimated that $7 \%$ of the general population have chronic HBV infection [24]. A meta-analysis estimates the prevalence of $1.9 \%$ for $\mathrm{HBV}$ and $1.1 \%$ for $\mathrm{HCV}$ in general population [25]. The proportion of HBV in IDUs ranged from 5.8-6.5\%, with an overall prevalence of $6.15 \%$ while the prevalence of HCV in same population was $36.4 \%$ [26]. In addition the prevalence of HCV and HBV in Female Sex Workers (FSWs) in three big cities in the country was $1.92 \%$, and $6.54 \%$ respectively [27]. A genotype study reported that genotype $\mathrm{D}$ is the predominant genotype circulating in Afghani's population after which the genotypes C, A and B predominates [28]. The Human Immunodeficiency Virus (HIV) epidemic is widespread throughout many countries in Asia. Many of the same risk factors, which facilitate the virus transmission in these countries, are also present in Afghanistan. The burden of HIV epidemic is low and mostly prevalent in high risk groups in the country. A survey of HIV 2012 showed that prevalence of HIV among people with injecting drug user was $4.4 \%$ while it was $0.4 \%$ among male sex workers, $0.3 \%$ among female sex workers and $0.7 \%$ among prisoners [29]. The cumulative number of HIV infections until 2012 were reported to be 1529 by sex ration of $6: 1$ male to female [30]. However, Joint United Nations Program on HIV/AIDS (UNAIDS) and the World Health Organization (WHO) estimates around 4,300 (1,600-14,000) number of people are living with HIV (PLHIV) in the country [21].

\section{METHODS AND MATERIALS}

The main study was a provincial cross sectional survey by design and the target population were all residents 25-70 years old living in urban areas of Kandahar city. Ethical approval was obtained from Ministry of Public Health Institutional Review Board (IRB). Temporary residents (resident $<6$ months) and those living in institutionalized settings or insecure areas were excluded. We used the WHO STEP-wise tool which included demographic, behavioral and biochemical domains and basically designed for non-communicable diseases. Using this opportunity we included some main variables related to hepatitis and HIV infection in the questionnaires and analysis were performed separately. Due to the unavailability of previous estimates of risk factor prevalence in this city we assumed the highest prevalence or sample size calculation $(50 \%)$, 95\% confidence interval (CI) and margin of error of 5\%. From this we estimated 385 subjects to be included in the survey. Taking into consideration the proportion of other risk factors in similar settings, the number of subjects was increased to 600. Finally, after taking into account the design effect (two) of cluster sampling the final sample size was increased to 1200 for the city, which was reasonable for achieving the study objectives with limited resources and funding support. Worth of mentioning that the sample size was originally calculated for risk factors of non-communicable diseases in main study. The Expanded Programme for Immunization (EPI) list of the clusters was used due to its reliability in Ministry of Public Health. As sampling strategy initially we got 
the list of all existed EPI clusters which included village/area name, population, and number of households per cluster. In the first stage of cluster sampling, we randomly selected 7 clusters of EPI using random number of excel sheet. In the second stage from each selected Cluster we randomly selected the five areas (called Area/Guzar). Later the whole sample of households distributed among selected area according to the proportion to the size of household number in each cluster / areas. Finally, the number of households in each area divided by the sample size assigned for each areas, it enabled us to select household systematically. Very participants gave written informed consent, after being explained the study objectives and procedures. Subjects were visited at home by interviewers and data on demographic, socio-demographic, lifestyle, and behaviors were collected. This was followed by anthropometric measurements taken by trained healthcare staff of institute of health science. Height and weight were measured using portable electronic weighing scale and measuring inflexible bars. Waist circumference was measured at the midpoint between the lower part of the lowest rib and the highest point of the hip on the mid-axillary line and blood pressure measured with a calibrated sphygmomanometer. Finally, blood samples were collected for biochemical and rapid testing for HBV, HCV and HIV infections. Samples were transported in cool boxes $\left(2-8^{\circ} \mathrm{C}\right)$ from field to public health Laboratory on the day of sample collection where it was processed and serum was separated and shipped to Central Public Health Laboratory (CPHL) in Kabul. Using Cry-vials the samples were coded. On arrival in CPHL all serum samples were stored at $-80^{\circ} \mathrm{C}$ until biochemical test conducted. Altogether 1165 samples were tested for biochemical measurement and rapid testing of hepatitis $\mathrm{B}, \mathrm{C}$ and HIV infections. Viral serology included HBsAg and hepatitis C antibodies (HCV-Ab) and HIV rapid tests. Data were analyzed using the Statistical Package for Social Science software (SPSS Version 20.0). Due to low number of cases both for HBV and HCV it was not logical to perform univariate analysis for differences in proportions of categorical variables between two groups. However, we described all demographic, socioeconomic and behavioral factors with respect to infections.

\section{RESULTS}

Data were validated and cleaned ahead of analysis for 1165 records. Of total records females constituted almost half $597(51.2 \%)$ with overall mean age of $38.3 \pm 11.2$ years. The results of rapid test were not available for both HBV and HCV for 12 samples due being poor samples (9) or missed ones (3). The prevalence of HBV was $2 \%$ (22 out of 1153) for HBsAg on rapid test. Totally 12 subject (1\%) were seropositive for antiHCV on rapid tests. None of subjects had co-infections. None of specimen were positive for HIV infection showed zero prevalence. Probably the cases will be changed if further confirmatory test are done on positive or negative cases. Most of the study participants were married $(79.3 \%)$, illiteracy rate was $73.2 \%$ and $88.5 \%$ of women were at home doing housework. About one tenth $(9.7 \%)$ were smokers and $16.3 \%$ were snuffers. The detail description is given in Table 1.In this study information regarding some risky behaviors for blood born viral infections including hepatitis and HIV/AIDS were collected. Two third of study subjects knew about hepatitis; in last six month ahead of field data collection $2.2 \%$ had blood transfusion; $5.3 \%$ had undergone surgery procedures and $16.8 \%$ undergone dental procedures. History of having jaundice was prevalent in $3.2 \%$ while one fourth of them had taken injection in last six months. Some behaviors such as piercing and traditional tattooing was reported in $33.2 \%$ and $5.5 \%$ of study subjects respectively. Almost one in twenty went to hospitals and $8.4 \%$ had lived with a person who had hepatitis. Coverage of vaccination for hepatitis B was 8.7\%. Almost one third of participants $(28.1 \%)$ went to simple barber shops (Table 2).

Due to low number or percentage of cases including HBV and HCV it was difficult to establish any associations, however we conduct chi-square and logistic regression and could not found any relationship of outcome and risk factors listed. Notwithstanding the prevalence of factors distribution among study subjects including positive and negative cases are described in Table 3. HBV and HCV as more prevalent (43.5\% and $50 \%$ ) in young age group (25-34 years) as compare to other groups. Hepatitis B were more prevalent in males $(60.9 \%)$ and hepatitis C prevalence was high in females $(66.7 \%)$. The proportion of HBV was $70 \%$ in illiterate group while there was no case of HCV recorded in whole participants who were literate. More than half of the cases had knowledge of both HBV and HCV while this proportion was low in negative cases for HBV versus $\mathrm{HCV}$. The positive cases of HBV undergone two-fold blood transfusion and dental procedures. The positive cases of HCV undergone three time (16.7\%) more procedures of surgery versus negative cases $(5.3 \%)$. The proportion of history of jaundice was $8.3 \%$ in cases of $\mathrm{HCV}$ and $4.3 \%$ in cases of HBV. Almost one fourth of study subjects including positive and negative cases had taken injections in last six months. Half of HCV cases had practice of piercing while this was lower (one third) in cases of HBV. 8.7\% of HBV cases practiced traditional tattooing while none of $\mathrm{HCV}$ cases practiced that. Equal proportion $(8.3 \%$ and $8.7 \%)$ of $\mathrm{HBV}$ and HCV cases had lived with hepatitis patients (Table 3 ).

\section{DISCUSSION}

Due to years and war and conflict there has been paucity of information in all aspects of social sector including health in Afghanistan. Few epidemiological information is available on clinical and public health 
aspects and extent of HBV and HCV infections in Afghanistan. The prevalence of HBV (2\%) and HCV (1\%) is very low in adult citizens of Kandahar province while it was $3.8 \%$ for HBV and $0.9 \%$ for HCV in Jalalabad city. Furthermore no case of HIV infection reported by this study and same zero prevalence found in Jalalabad city [22]. Probably that would be due validity of rapid test which will require more confirmatory tests in advance analytical studies. Identification of such prevalence in adult population is first of its kind in this city but still due to lack of data from large parts of county efforts are required to strengthen national surveillance supported by lab components to assess the exact situation of viral hepatitis. It seems the country is at an early phase of HBV and HCV prevalence, however load of high risk groups with worst situations has made the country vulnerable to future epidemics. There is just national control program of tuberculosis, HIV/AIDS and malaria while this program is lacking for hepatitis in the country. Based on our findings those who were positive at rapid test for $\mathrm{HBV}$ and HCV were young generation which is not statistically significant. It could be due to involvement of young groups in using of injections drugs which is a key driver of blood born viral transmission and probably owing to sharing the needles [31-32]. Furthermore, those who have been refugees in neighbouring countries and return back probably are infected and could pose communities at more risk of disease. According to finding of this study the blood transfusion has been double in infected versus non- infected with HBV. The weak health systems and poor infection preventions practices in health centres would seem favourable to a rapid spread of these diseases. Focusing on occupational safety and health training to health workers as well as proper waste management at health s settings is recommended elsewhere [33]. Tattooing and dental producers along with hospitalization were higher in percentage among positive cases versus negative cases. This finding is supported by other studies as well [34]. History of jaundice was also prevalent in positive cases versus negative cases which shows possibly cases have been exposed to viral hepatitis which is supported by other studies [35-26].

The prevalence of HBV and HCV which shows the low rate of disease in this city should not encourage us to rest in complacency and still it requires to formulate interventions for control and preventions of all blood born viral diseases. The stakeholders and policy makers are needed to design and implement effective programs for early interventions to prevent the spread of hepatitis in Afghanistan. Focusing on behavioural and biological surveillance is important and raising awareness for vaccination is also of value.

\section{ACKNOWLEDGEMENTS}

The author express gratitude to Surveillance Department at the Ministry of Public Health and the WHO Kabul office for supporting the main study. The CPHL is acknowledged for their processing and testing of $\mathrm{HBV}, \mathrm{HCV}$ and HIV infections.

\section{REFERENCES}

[1] Chan O, Lao, T, Suen S. \&Yeung T. (2012). Deficient Knowledge on Hepatitis B Infection in Pregnant Women and Prevalence of Hepatitis B Surface Antigen Carriage in an Endemic Area, A Review, Hepatitis Research and Treatment, 2012. Article ID 317451., 8 pages

[2] Navabakhsh, B., Mehrabi, N., Estakhri, A., Mohamadnejad, M. \&Poustchi, H. (2011). Hepatitis B Virus Infection during Pregnancy, Transmission and Prevention, Middle East Journal of Digestive Diseases. 3(2), 92-102.

[3] Burler JRG, Korda RJ, Watson KJR, Watson DAR. The impact of chronic Hepatitis in Australia: projecting mortality, morbidity and economic impact. Canberra. Australian Center for Economic Research on Health, 200

[4] Liaw YF, Chu CM. Hepatitis B virus infection. Lancet. 2009; 373(9663):582-92.

[5] Morgan M, Keeffe EB. Diagnosis and treatment of chronic hepatitis B: 2009 update. Minerva GastroenterolDietol. 2009;55(1):5-22.

[6] Custer B, Sullivan SD, Hazlet TK, Iloeje U, Veenstra DL, Kowdley KV. Global epidemiology of hepatitis B virus. J ClinGastroenterol. 2004;38(10 Suppl 3):S158-68.

[7] Lok AS. Chronic hepatitis B. N Engl J Med. 2002;346(22):1682-3.

[8] Knipe DM, Howley P (2013) Fields virology. Philadelphia: Wolters Kluwer Health/Lippincott Williams $\&$ Wilkins.

[9] Goldstein ST, Zhou F, Hadler SC, Bell BP, Mast EE, et al. (2005) A mathematical model to estimate global hepatitis B disease burden and vaccination impact. Int J Epidemiol 34: 1329-1339.

[10] Kowdley KV (2004) The cost of managing chronic hepatitis B infection: a global perspective. J ClinGastroenterol 38: S132-S133.

[11] Nicoletta P, Daniel L (2002) Hepatitis B. World Health Organization.

$\begin{array}{llllll}\text { [12] WHO. Hepatitis } & \mathrm{C} & \text { fact } & \text { Available } & \text { from: } \\ \text { http://www.who.int/mediacentre/factsheets/fs164/en/index.html } & & & \text { from }\end{array}$ 
[13] Hayashi J, Kishihara Y, Yamaji K, Yoshimura E, Kawakami Y, Akazawa K, et al. Transmission of hepatitis $\mathrm{C}$ virus by health care workers in a rural area of Japan. The American journal of gastroenterology. 1995;90(5):794.

[14] World Health Organization, 2012. Prevention and control of viral hepatitis infection: framework for global action, 2012. Available at: http://www.who.int/csr/disease/hepatitis/ GHP_Framework_En.pdf?ua=1.

[15] Mortality and Causes of Death Collaborators. Global, regional, and national age-sex specific all-cause and cause-specific mortality for 240 causes of death, 1990-2013: a systematic analysis for the Global Burden of Disease Study 2015. Lancet 2013; 385(9963): 117-171.

[16] Ashfaq UA, Javed T, Rehman S, Nawaz Z, Riazuddin S. An overview of HCV molecular biology, replication and immune responses. Virology journal. 2011;8:161.

[17] Ali SA, Donahue RMJ , Qureshi H , Vermund SH. Hepatitis B and hepatitis C in Pakistan: prevalence and risk factors. International Journal of Infectious Diseases (2009) 13, 9-19UNAIDS Global AIDS Report 2013

[18] Qirbi N, Hall A (2001). Epidemiology of hepatitis B virus infection in the Middle East. East Mediterr Health J 2001, 7(6):1034-1045.

[19] Anwar MI, Rahman M, Hassan M, Iqbal M (2013). Prevalence of active hepatitis C virus infections among general public of Lahore, Pakistan. Virology Journal, 10:351

[20] Khan MS, Jamil M, Jan S, Zardad S, Sultan S, Sahibzada AS (2007). Prevalence of hepatitis 'B' and 'C' in orthopedics Patients at Ayub teaching hospital Abbottabad. J Ayub Med Coll Abbottabad 2007;19(4)

[21] UNAIDS HIV and AIDS 2012: http://www.unaids.org/en/regionscountries/countries/afghanistan/

[22] Saeed, Khwaja Mir Islam. Prevalence and Associated Factors of Hepatitis B, Hepatitis C and HIV Infection in Jalalabad City, Afghanistan. GMJ 2016 ;01(6): pp62-74

[23] Todd CS, et al (2009). Prevalence and correlates of HIV, syphilis, and hepatitis knowledge among intrapartum patients and health care providers in Kabul, Afghanistan. AIDS Care; 21:109-1.

[24] MoPH (2005). Introduction of Hepatitis B Vaccine in Afghanistan, Ministry of Public Health (MoPH), Afghanistan 2005

[25] Khan S, Attaullah S (2011). Share of Afghanistan populace in hepatitis B and hepatitis C infection's pool: is it worthwhile Virology Journal, 8:216

[26] Nasir A et al (2011). Prevalence of HIV, hepatitis B and hepatitis C and associated risk behaviors amongst injecting drug users in three Afghan cities. Int J Drug Policy, 22(2):145-52.

[27] Todd CS et al (2010). HIV, hepatitis B, and hepatitis C prevalence and associated risk behaviors among female sex workers in three Afghan cities. AIDS, 24:S69-S75.

[28] Attaullah S, Rehman S, Khan S, Ali I, Ali S, Khan SN (2011). Prevalence of Hepatitis B virus genotypes in HBsAg positive individuals of Afghanistan. Virology Journal 8:281.

[29] MoPH, NACP, IBBS, 2012

[30] National HIV/AIDS Control Program (NACP). Country Progress Report Afghanistan. Ministry of Public Health, 2014

[31] United Nations General Assembly Special Session on HIV/AIDS, Country Progress Report (Reporting Period January 2008 to December 2009). Islamic Republic of Afghanistan; 2010.

[32] Todd CS, Ahmadzai M, Atiqzai F, Miller S, Smith JM, Ghazanfar SA, Strathdee SA: Seroprevalence and correlates of HIV, syphilis, and hepatitis B and C virus among intrapartum patients in Kabul, Afghanistan. BMC Infect Dis 2008, 17(8):119.

[33] Kitt MM, Khalid G, Rahimi S, McCarthy BJ: An Occupational Health Services Initiative at a Women's Hospital in Kabul. Afghanistan Public Health Rep 2006, 121(6):650-657.

[34] Ghadir, MR et al (2012). Distribution and Risk Factors of Hepatitis B Virus Infection in the General Population of Central Iran. Hepatitis Monthly, Vol. 12 Issue 2, p112

[35] Pasha O, Luby SP, Khan AJ, Shah SA, McCormick JB, Fisher-Hoch SP. Household members of hepatitis C virus-infected people in Hafizabad, Pakistan: infection by injections from health care providers. Epidemiol Infect 1999; 123:515-8.

[36] Akhtar S, Moatter T, Azam SI, Rahbar MH, Adil S. Prevalence and risk factors for intrafamilial transmission of hepatitis C virus in Karachi, Pakistan. J Viral Hepat 2002; 9:309—14. 


\begin{tabular}{|c|c|c|c|c|c|c|c|}
\hline \multirow{2}{*}{$\begin{array}{r}\text { Table } \\
\text { Variables } \\
\end{array}$} & \multirow{2}{*}{ Categories } & \multicolumn{2}{|c|}{ Male } & \multicolumn{2}{|c|}{ Female } & \multicolumn{2}{|c|}{ Total } \\
\hline & & $\mathbf{N}$ & $\%$ & $\mathbf{N}$ & $\%$ & $\mathbf{N}$ & $\%$ \\
\hline \multicolumn{8}{|l|}{ Age } \\
\hline & $25-34$ & 248 & 43.7 & 272 & 45.6 & 520 & 44.6 \\
\hline & $35-44$ & 162 & 28.5 & 161 & 27 & 323 & 27.7 \\
\hline & $45-54$ & 94 & 16.5 & 94 & 15.7 & 188 & 16.1 \\
\hline & $55+$ & 64 & 11.3 & 70 & 11.7 & 134 & 11.5 \\
\hline \multicolumn{8}{|c|}{ Level of Education } \\
\hline & Illiterate & 307 & 5.6 & 533 & 89.4 & 840 & 73.2 \\
\hline & Primary and unofficial & 111 & 20.1 & 53 & 8.9 & 164 & 14.3 \\
\hline & Secondary school & 68 & 12.3 & 4 & 0.7 & 72 & 6.3 \\
\hline & High school and over & 66 & 12 & 6 & 1 & 72 & 6.3 \\
\hline \multicolumn{8}{|c|}{ Work Status } \\
\hline & Official Employees & 114 & 25.7 & 11 & 2.4 & 125 & 13.8 \\
\hline & Private Business & 104 & 23.4 & 6 & 1.3 & 110 & 12.1 \\
\hline & Worker/Farmer & 130 & 29.3 & 0 & 0 & 130 & 14.3 \\
\hline & Jobless & 73 & 16.4 & 19 & 4.1 & 92 & 10.2 \\
\hline & Housework & 5 & 1.1 & 409 & 88.5 & 414 & 45.7 \\
\hline & Unable to work & 18 & 4.1 & 17 & 3.7 & 35 & 3.9 \\
\hline \multicolumn{8}{|c|}{ Monthly Income in AFN } \\
\hline & Less than 10000 & 15 & 32.6 & 25 & 51 & 40 & 42.1 \\
\hline & More than 10000 & 31 & 67.4 & 24 & 49 & 55 & 57.9 \\
\hline \multicolumn{8}{|c|}{ Marital Status } \\
\hline & Single & 95 & 16.8 & 25 & 4.2 & 120 & 10.3 \\
\hline & Married & 435 & 76.9 & 487 & 81.6 & 922 & 79.3 \\
\hline & Widow/Widower & 9 & 1.6 & 66 & 11.1 & 75 & 6.4 \\
\hline & Divorced & 0 & 0 & 6 & 1 & 6 & 0.5 \\
\hline & Refused & 27 & 4.8 & 13 & 2.2 & 40 & 3.4 \\
\hline \multicolumn{8}{|c|}{ Cigarette Smoking Status } \\
\hline & No & 468 & 82.4 & 584 & 97.8 & 1052 & 90.3 \\
\hline & Yes & 100 & 17.6 & 13 & 2.2 & 113 & 9.7 \\
\hline \multicolumn{8}{|c|}{ Mouth Snuff Status } \\
\hline & No & 399 & 70.5 & 574 & 96.3 & 973 & 83.7 \\
\hline & Yes & 167 & 29.5 & 22 & 3.7 & 189 & 16.3 \\
\hline
\end{tabular}

\begin{tabular}{|c|c|c|c|c|c|c|c|}
\hline \multicolumn{8}{|c|}{ Table 2: Behavioral characteristics of study participants in Kandahar city } \\
\hline \multirow[t]{2}{*}{ Variables } & \multirow[t]{2}{*}{ Groups } & \multicolumn{2}{|c|}{ Female } & \multicolumn{2}{|c|}{ Male } & \multicolumn{2}{|c|}{ Total } \\
\hline & & $\mathrm{N}$ & $\%$ & $\mathrm{~N}$ & $\%$ & $\mathrm{~N}$ & $\%$ \\
\hline \multicolumn{8}{|c|}{ Knowledge of Hepatitis } \\
\hline & No & 215 & 36.1 & 233 & 41 & 448 & 38.5 \\
\hline & Yes & 381 & 63.9 & 335 & 59 & 716 & 61.5 \\
\hline \multicolumn{8}{|c|}{ Blood Transfusion } \\
\hline & No & 577 & 97.6 & 556 & 98.1 & 1133 & 97.8 \\
\hline & Yes & 14 & 2.4 & 11 & 1.9 & 25 & 2.2 \\
\hline \multicolumn{8}{|c|}{ Surgery Procedure } \\
\hline & No & 569 & 95.3 & 533 & 94 & 1102 & 94.7 \\
\hline & Yes & 28 & 4.7 & 34 & 6 & 62 & 5.3 \\
\hline \multicolumn{8}{|c|}{ Dental Procedure } \\
\hline & No & 517 & 86.6 & 452 & 79.6 & 969 & 83.2 \\
\hline & Yes & 80 & 13.4 & 116 & 20.4 & 196 & 16.8 \\
\hline
\end{tabular}


Burden Of Hepatitis B, Hepatitis C And HIV Infections Among

\begin{tabular}{|l|l|r|r|r|r|r|r|r|}
\hline & No & 569 & 95.6 & 554 & 98.1 & 1123 & 96.8 \\
\hline & Yes & 26 & 4.4 & 11 & 1.9 & 37 & 3.2 \\
\hline Needle Injection & No & 411 & 69.2 & 452 & 79.9 & 863 & 74.4 \\
\hline & Yes & 183 & 30.8 & 114 & 20.1 & 297 & 25.6 \\
\hline & No & 378 & 64.2 & 388 & 69.5 & 766 & 66.8 \\
\hline Piercing & Yes & 211 & 35.8 & 170 & 30.5 & 381 & 33.2 \\
\hline & No & 557 & 93.5 & 542 & 95.6 & 1099 & 94.5 \\
\hline \multicolumn{7}{|l|}{} \\
\hline
\end{tabular}

Table 3: Hepatitis B virus infection status and its distribution based on socieodemographic factors in study participants in Kandahar city

\begin{tabular}{|c|c|c|c|c|c|c|c|c|c|}
\hline \multirow[t]{2}{*}{ Variables } & \multirow[t]{2}{*}{ Groups } & \multicolumn{2}{|c|}{ HBV Negative } & \multicolumn{2}{|c|}{ HBV Positive } & \multicolumn{2}{|c|}{ HCV Negative } & \multicolumn{2}{|c|}{ HCV positive } \\
\hline & & $\mathbf{N}$ & $\%$ & $\mathbf{N}$ & $\%$ & $\mathbf{N}$ & $\%$ & $\mathbf{N}$ & $\%$ \\
\hline \multicolumn{10}{|c|}{ Age in years } \\
\hline & $25-34$ & 505 & 44.7 & 10 & 43.5 & 509 & 44.6 & 6 & 50 \\
\hline & $35-44$ & 315 & 27.9 & 5 & 21.7 & 316 & 27.7 & 4 & 33.3 \\
\hline & $45-54$ & 180 & 15.9 & 4 & 17.4 & 183 & 16 & 1 & 8.3 \\
\hline & 54 and over & 130 & 11.5 & 4 & 17.4 & 133 & 11.7 & 1 & 8.3 \\
\hline \multicolumn{10}{|l|}{ Sex } \\
\hline & Female & 580 & 51.3 & 9 & 39.1 & 581 & 50.9 & 8 & 66.7 \\
\hline & Male & 550 & 48.7 & 14 & 60.9 & 560 & 49.1 & 4 & 33.3 \\
\hline \multicolumn{10}{|c|}{ Level of education } \\
\hline & Illiterate & 816 & 73.3 & 16 & 69.6 & 820 & 73 & 12 & 100 \\
\hline & Literate & 297 & 26.7 & 7 & 30.4 & 304 & 27 & 0 & 0 \\
\hline \multicolumn{10}{|c|}{ Knowledge of Hepatitis } \\
\hline & No & 434 & 38.4 & 11 & 47.8 & 441 & 38.7 & 4 & 33.3 \\
\hline & Yes & 695 & 61.6 & 12 & 52.2 & 699 & 61.3 & 8 & 66.7 \\
\hline \multicolumn{10}{|c|}{ Blood Transfusion } \\
\hline & No & 1099 & 97.9 & 22 & 95.7 & 1109 & 97.8 & 12 & 100 \\
\hline & Yes & 24 & 2.1 & 1 & 4.3 & 25 & 2.2 & 0 & 0 \\
\hline \multicolumn{10}{|c|}{ Surgery Procedure } \\
\hline & No & 1068 & 94.6 & 22 & 95.7 & 1080 & 94.7 & 10 & 83.3 \\
\hline & Yes & 61 & 5.4 & 1 & 4.3 & 60 & 5.3 & 2 & 16.7 \\
\hline \multicolumn{10}{|c|}{ Dental Procedure } \\
\hline & No & 938 & 83 & 21 & 91.3 & 950 & 83.3 & 9 & 75 \\
\hline
\end{tabular}


Burden Of Hepatitis B, Hepatitis C And HIV Infections Among

\begin{tabular}{|l|l|l|l|l|l|l|l|l|l|}
\hline & Yes & 192 & 17 & 2 & 8.7 & 191 & 16.7 & 3 & 25 \\
\hline History of Jaundice & No & 1090 & 96.9 & 22 & 95.7 & 1101 & 96.9 & 11 & 91.7 \\
\hline & Yes & 35 & 3.1 & 1 & 4.3 & 35 & 3.1 & 1 & 8.3 \\
\hline & No & 837 & 74.4 & 17 & 73.9 & 845 & 74.4 & 9 & 75 \\
\hline & Yes & 288 & 25.6 & 6 & 26.1 & 291 & 25.6 & 3 & 25 \\
\hline \multicolumn{7}{|l|}{} \\
\hline
\end{tabular}

